\title{
Barry Cockcroft to take the helm at BFS
}

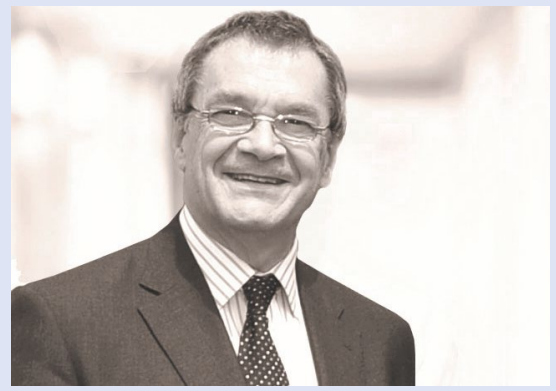

The current Chairman of the British Fluoridation Society (BFS), Steve Bedser, is standing down after leading the organisation for five years. Dr Barry Cockcroft CBE, who was elected to the BFS Executive in 2020, has agreed to take over from Steve in an interim capacity until a formal election can take place at the BFS AGM later this year.

Steve's contribution to the BFS has been significant. When the Health and Social Care Act of 2012 came into being, public health became the responsibility of local authorities. Steve, who was on
Birmingham City Council's Health and Wellbeing Board at the time, understood the role of water fluoridation in reducing oral health inequalities. Birmingham had been the first city in the UK to have its water supply fluoridated and inspired the formation of the BFS with its mission to drive up targeted water fluoridation schemes across the UK. Steve wanted to be part of that work and joined BFS before being elected as Chair soon afterwards.

The White Paper announced in February, paving the way for new legislation, signalled that the Government plans to take back control of water fluoridation schemes. ${ }^{1}$

Dr Cockcroft (pictured), the former Chief Dental Officer for England, who joined BFS in 2006, said: 'Research has repeatedly shown that water fluoridation reduces oral health inequalities and it is the most costeffective way to improve oral health. The BFS is delighted by the unequivocal support of Secretary of State for Health Matt Hancock for water fluoridation.
'We will now be working to support the Government when it proposes new schemes and will also be watching the passage of legislation through the Parliamentary process. I am delighted to be taking on the Chairman's role at this critical time.'

After paying tribute to Steve Bedser for his work on behalf of BFS, Dr Cockcroft added: 'No announcement at this time would be complete without mentioning the late Mike Lennon, who passed away on 9 April. As Chairman of BFS for 20 years, he did so much to make the Society an internationally respected authority on water fluoridation. Plans are being developed to celebrate his achievements.'

\section{Reference}

1. Department of Health and Social Care. Working together to improve health and social care for all. 11 February 2021. Available at: https://www.gov. uk/government/publications/working-together-toimprove-health-and-social-care-for-all (accessed April 2021). 